\title{
THE ATS-F/NIMBUS-E TRACKING EXPERIMENT
}

\author{
F. O. VON BUN \\ National Aeronautics and Space Administration Washington, D.C., Goddard Space Flight Center, \\ Trajectory Analysis and Geodynamics Division
}

\begin{abstract}
In this paper the objective of the ATS-F/NIMBUS-E Tracking Experiment, the first of such kind, is presented. Specifically, this experiment has a two-fold purpose: First, to gain experience in the practical use of satellite-to-satellite range and range rate data for very accurate orbit determination (this was its original intent); and second, to evaluate the real usefulness of such a technique for geodetic studies despite the fact that the $1000 \mathrm{~km}$ NIMBUS orbit is not ideally suited for such a purpose.

The accuracies of the tracking systems of the satellite-to-satellite and satellite-to-ground link (ATS-F to the Rosman, N.C. ground station) will be $\sim 0.035 \mathrm{~cm} / \mathrm{s}$ in range rate and $\sim 1 \mathrm{~m}$ in range utilizing a $10 \mathrm{~s}$ integration time. With these values one obtains, based upon performed error analyses, orbit height errors in the order of 0.1 to $0.3 \mathrm{~m}$ for the near earth orbiting NIMBUS spacecraft. This experiment will therefore hopefully prove to be a significant first step for future Earth applications spacecraft carrying altimeters systems for measuring ocean height variations.

In addition, laser corner reflectors placed on board the ATS-F will make a total independent position determination of this spacecraft to approximately $15 \mathrm{~m}$ to $30 \mathrm{~m}$ possible, assuming that the location errors of four laser tracking stations used to determine the orbit are about $3 \mathrm{~m}$ or $5 \mathrm{~m}$ in each component respectively, with laser ranging system noise errors of $1.2 \mathrm{~m}$ and bias errors of $0.15 \mathrm{~m}$. A small position error of the ATS-F, the 'orbiting tracking station'. is essential in order to make full usage of the small satellite-to-satellite tracking errors mentioned.

For purpose of geodetic studies, one of the final goals, range rate variations of $0.1 \mathrm{~cm} / \mathrm{s}$ or less corresponding to surface gravity anomaly of $20 \mathrm{mgal}$ or less (over a half-width of $100 \mathrm{~km}$ on the Earth surface), will have to be measured during a time interval of approximately, say, 30-60 s. These values are within the range of the planned tracking systems accuracies for ATS-F and NIMBUS-E.
\end{abstract}

In this paper, the objective of the first satellite-to-satellite tracking experiment is presented. The spacecraft involved will be the ATS-F and the NIMBUS-E. Specifically, this experiment has a two-fold purpose: (1) to gain experience in using satelliteto-satellite range and range rate data for very accurate orbit determination (von Bun and Mengel, 1968; GSFC, 1969) (this was its original intent), and (2) to evaluate the real usefulness of such a technique for geodetic studies (NASA report, 1970, 1971; von Bun, 1969; Martin, 1969).

It should be pointed out at this time, that the orbit for NIMBUS-E with a height of $\sim 800$ to $1000 \mathrm{~km}$ is a good one for orbital studies but not an ideal one for gravitational studies.

The first portion of this paper, as indicated, deals with the tracking and orbit determination problems of both the ATS-F and the NIMBUS-E spacecraft. In particular the orbital errors will be discussed as a function of ground station location errors and errors in the tracking systems used. Second, the usefulness of a satelliteto-satellite range rate system to detect gravity anomalies over short wave length ( $\sim 400 \mathrm{~km}$ or so) will be briefly outlined.

The tracking geometry for this experiment is depicted in Figure 1 showing four tracking stations, namely, Rosman, Mojave, Santiago and Ascension. Only two, Rosman and Mojave, are being equipped with electronic range and range rate systems 


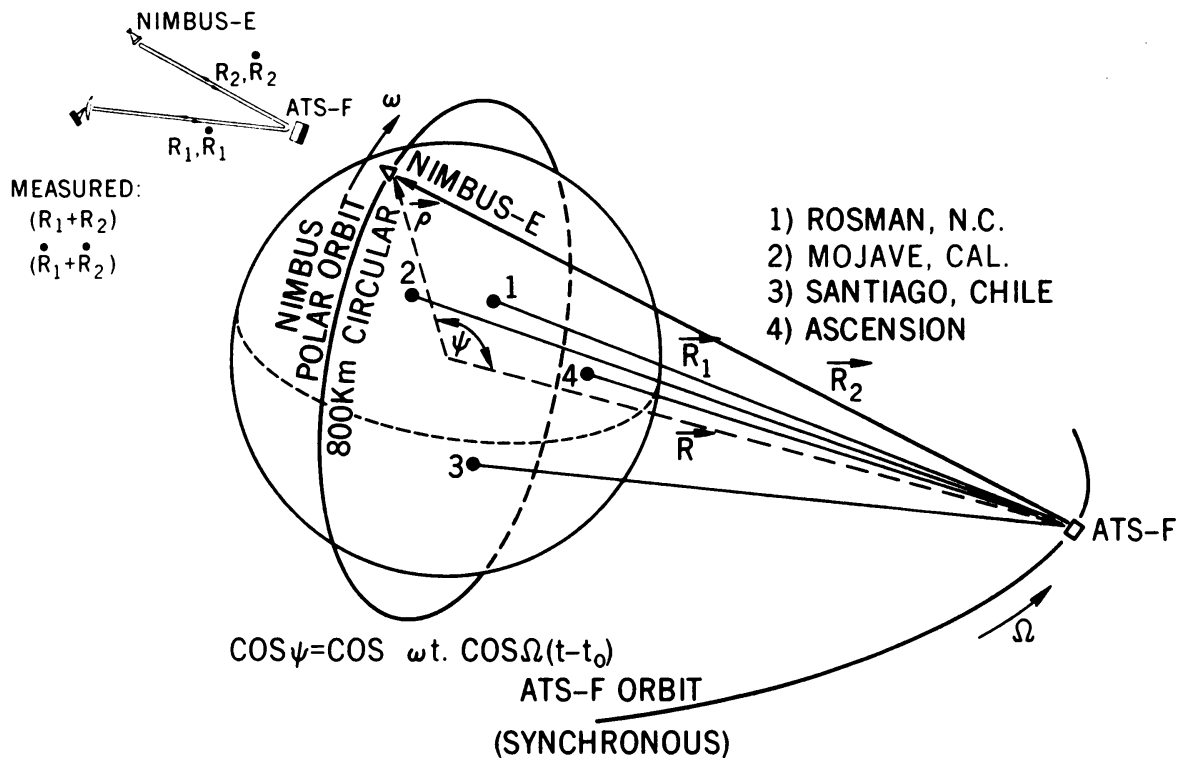

Fig. 1. Tracking geometry for ATS-F and NIMBUS-E.

and thus will be used during the actual experiment. The two additional stations are at present only fictional and were used in a laser ranging error analysis study to get a feel for the ATS orbital errors one can expect using three or four laser stations for tracking. Please note that the ATS-F spacecraft will be equipped with an array of laser corner reflectors in order to make laser ground tracking possible. Figure 2 shows these orbit errors as a function of the errors in the location of the laser tracking stations (arbitrarily chosen). The assumed ranging error of $150 \mathrm{~cm}$ is very conservative. In the meantime, we have collected at Goddard more than 100000 ranging data with errors

\begin{tabular}{|r|c|c|c|c|}
\hline $\begin{array}{r}\text { STATION ERROR IN } \\
\text { EACH } \\
\text { TRACKING }\end{array}$ & 40 & 10 & 3 & 0 \\
STATIONS USED & $(\mathrm{m})$ & & & \\
\hline $\begin{array}{c}\text { ROSMAN, N.C.; } \\
\text { MOJAVE. CAL.: } \\
\text { SANTIAGO. CHILE }\end{array}$ & 520 & 140 & 45 & 2.6 \\
\hline SAME AND ASCENSION & 380 & 60 & 19 & 1.0 \\
\hline
\end{tabular}

LASER ERRORS: NOISE $=1.2 \mathrm{~m}$

SAMPLING RATE: $1 / \mathrm{min}$ $B I A S=0.15 \mathrm{~m}$

TRACKING TIME: 24h. (85\% OF THESE VALUES ARE OBTAINED BY 5 TO $6 \mathrm{~h}$ OF

TRACKING ONLY.)

OVER $90 \%$ OF THESE ERRORS ARE ALONG AND CROSSTRACK ERRORS.

Fig. 2. ATS-F laser tracking position errors vs station location errors. 


\begin{tabular}{|l|c|c|c|c|c|c|}
\cline { 2 - 7 } \multicolumn{1}{c|}{} & \multicolumn{3}{c|}{ ATS-F } & \multicolumn{3}{c|}{ NIMBUS-E } \\
\hline ROSMAN & $\begin{array}{c}\text { POSITION } \\
\mathrm{m}\end{array}$ & $\begin{array}{c}\text { VELOCITY } \\
\mathrm{cm} / \mathrm{s}\end{array}$ & $\begin{array}{c}\text { HEIGHT } \\
\mathrm{m}\end{array}$ & $\begin{array}{c}\text { POSITION } \\
\mathrm{m}\end{array}$ & $\begin{array}{c}\text { VELOCITY } \\
\mathrm{cm} / \mathrm{s}\end{array}$ & $\begin{array}{c}\text { HEIGHT } \\
\mathrm{m}\end{array}$ \\
\hline$\Delta \mathrm{X}_{i}, 3,3,3$ & 20 & 0.2 & 0.9 & 4 & 0.2 & 0.04 \\
& 30 & 0.3 & 2.1 & 6 & 0.4 & 0.13 \\
\hline $\mathrm{X}_{i}, 10,10,10$ & 25 & 0.3 & 2 & 5 & 0.4 & 0.1 \\
& 50 & 0.5 & 6 & 10 & 1.2 & 0.2 \\
\hline
\end{tabular}

$\begin{aligned} \delta \mathrm{r} & =1 \mathrm{~m} \\ \Delta \mathrm{r} & =1 \mathrm{~m} \\ \delta \mathrm{r} & =0.035 \mathrm{~cm} / \mathrm{s} \\ \Delta \mathrm{r} & =0.000 \mathrm{~cm} / \mathrm{s}\end{aligned}$

ATS-F, $-66^{\circ}$ ON EQUATOR.

STATION ERRORS NOT SOLVED FOR.

Fig. 3. ATS-F and NIMBUS-E orbit errors (for both orbits solved for simultaneously).

between 30 and $40 \mathrm{~cm}$ only (International Satellite Geodesy Experiment, ISAGEX).

Figure 3 shows the orbital errors of both the ATS-F and NIMBUS-E spacecraft using the Rosman station alone (in order to be on the conservative side). The second station, Mojave, California, will improve the values. The expected height errors of the near-Earth spacecraft are of particular interest for future missions carrying radar altimeters. As can be seen from Figure 3, height variations in the $\mathrm{d} m$ range may be

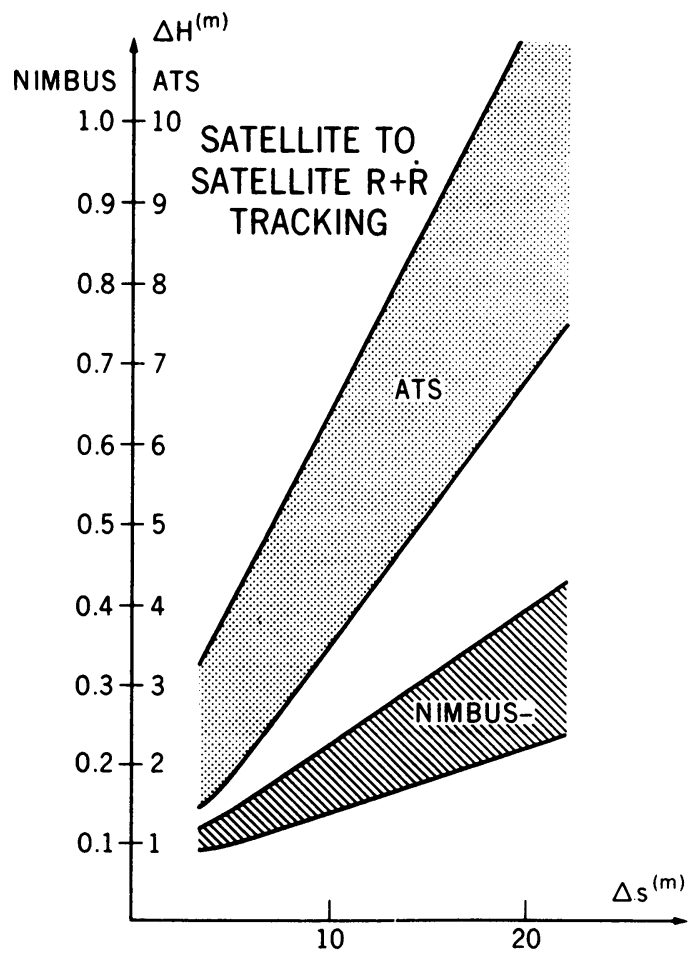

Fig. 4. ATS-F and NIMBUS-E height errors vs Rosman station errors. 
detected. Figure 4 shows the relationship between the height errors of ATS-F and NIMBUS-E as a function of the error in the location of the Rosman tracking station. The present best values for Rosman are $\sim 3$ to $5 \mathrm{~m}$ in each component.

Next, the usefulness of this experiment for geodetic purposes will be briefly investigated. As simply shown by Parasnis (1961) and first detected by Muller and Sjorgen (1968) using satellite techniques on the Moon, gravity anomalies on planetary surfaces can be described using density variations underneath the surface.

Assume a rather large anomaly, such as those to be found in the New Guinea area of say 200 mgals. Such an anomaly can be expressed by a relative mass of $\Delta \mathrm{m} / \mathrm{m}=$ $=5 \times 10^{-8}$ (in Earth masses) at a depth of $100 \mathrm{~km}$ (Parasnis, 1961).

Using $\Delta m$ 'buried' under the surface one can then write for the Earth's potential function:

$$
U^{*}=G \frac{(m-\Delta m)}{\varrho}+G \frac{\Delta m}{r} .
$$

where $G$ is the universal gravitational constant, $m$ is the Earth's mass, $\rho$ is the distance of the spacecraft from the center of the earth and $r$ is the distance between the mass $\Delta m$ and the spacecraft. A spherical Earth has been assumed as evidenced by Equation (1). Since the purpose here is to study the magnitudes of effects, this assumption is justified. It should, however, not be overlooked that in reality the gravity harmonics of the real Earth have similar effects to those of the motions of the spacecraft. However the different frequencies involved will help the solution.

For reasons of simplicity, assume that the spacecraft passes over the mass anomaly, one can then express the velocity changes $\Delta V_{e}$ in the radial and $\Delta V_{\theta}$ in the tangential direction in analytical form, that is:

and

$$
\begin{aligned}
& \Delta v_{e}=\int \frac{\partial \Delta U}{\partial \varrho} \mathrm{d} t \\
& \Delta v_{\theta}=\int \begin{array}{l}
1 \partial \Delta U \\
\varrho \partial \theta
\end{array} \mathrm{d} t
\end{aligned}
$$

$$
\Delta U=U^{*}-\frac{G m}{\varrho}
$$

where $\theta$ is the true anomaly. Assuming further a small eccentricity $(e \leqq 0.05)$ one obtains, after some rather cumbersome manipulations, the following expressions for:

$$
\begin{gathered}
\Delta v_{e}=-\frac{\Delta m}{m} v_{\text {hor }}\left[\frac{1+x}{2(1-x)^{2}} \frac{\Delta \theta}{\sqrt{1+\frac{x}{(1-x)^{2}} \Delta \theta^{2}}}+\right. \\
\quad+\frac{1}{2 \sqrt{x} \ln \left(\frac{\sqrt{x}}{1-x} \Delta \theta+\sqrt{\left.1+\frac{x}{(1-x)^{2}} \Delta \theta^{2}\right)}\right]} \\
\Delta v_{\theta}=\frac{\Delta m}{m} \frac{v_{\text {hor }}}{x}\left[\frac{1}{\left.\sqrt{1+x^{2}-2 x \cos \Delta \theta}-\frac{1}{(1-x)}\right]}\right.
\end{gathered}
$$




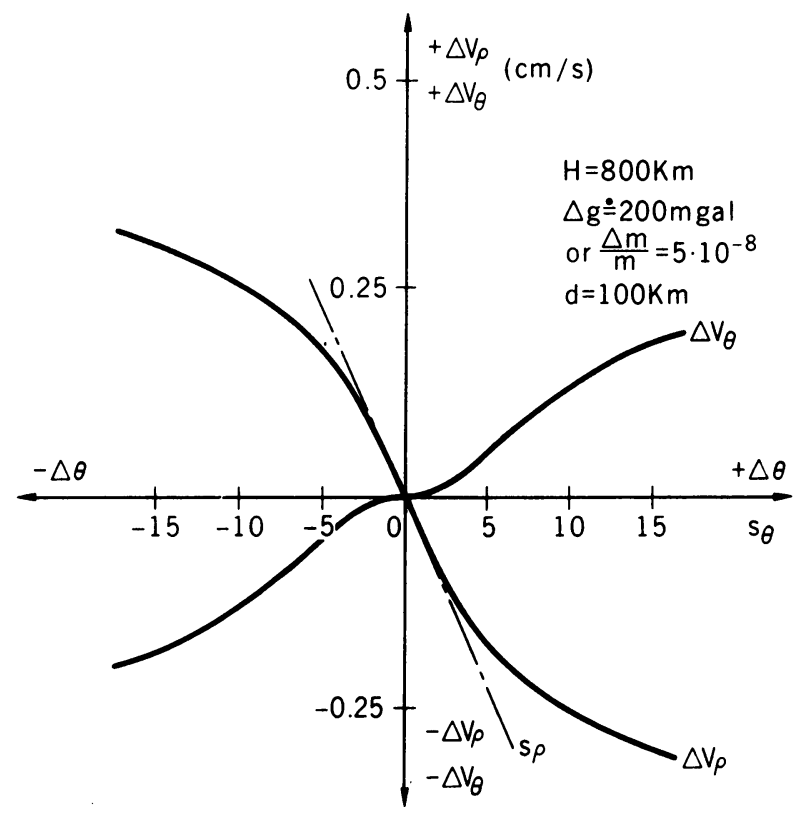

Fig. 5. Velocity variations $\Delta V_{\varrho}$ and $\Delta V_{\theta}$ as a function of $\Delta \theta$.

and

$$
x=\left(\frac{R-d}{R+H}\right)
$$

where $v_{\text {hor }}$ is the horizontal velocity of the spacecraft (approximately equal to the spacecraft velocity for small eccentricity), $R$ is the radius of the planet, $\mathrm{d}$ is the depth of the mascon of mass $\Delta m$, and $H$ is the height of the satellite orbit.

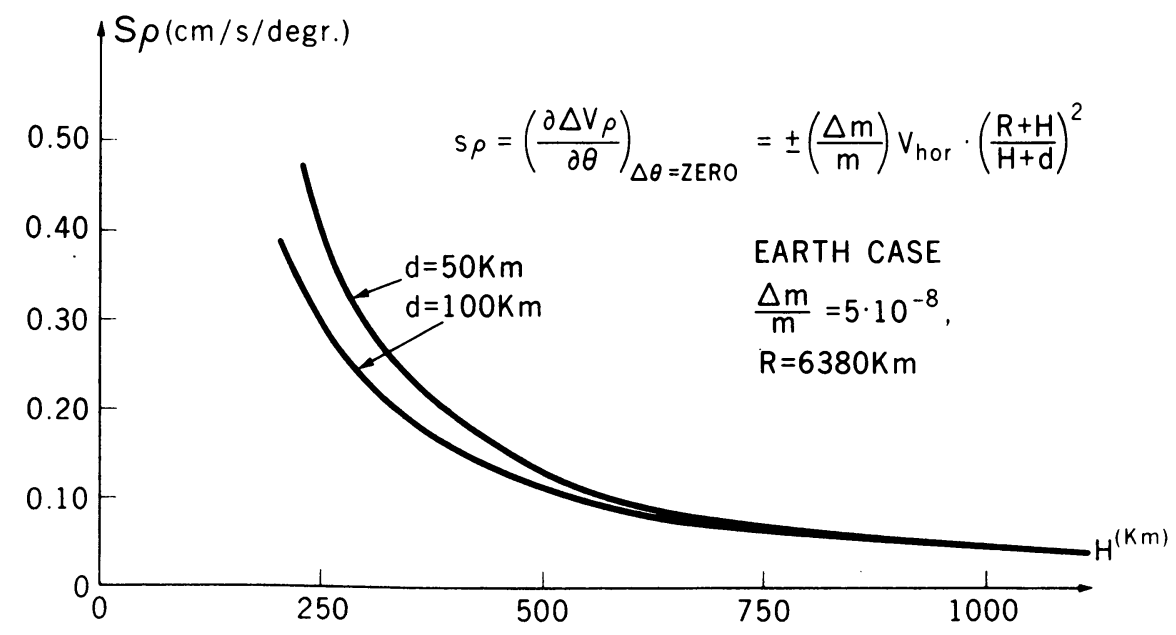

Fig. 6. Slope of radial velocity vs height. 
In addition, the slope (at the point when the spacecraft is just above the mascon) of the radial velocity change can further be obtained in rather simple form from (2):

$$
s_{e}=\left(\frac{\partial \Delta v_{e}}{\partial \theta}\right)_{\theta=0}=-\left(\frac{\Delta m}{m}\right) v_{\text {hor }}\left(\frac{R+H}{R+d}\right)^{2} .
$$

Figure 5 shows the velocity variations $\Delta v_{e}$ and $\Delta v_{\theta}$ as a function of $\Delta \theta$ (for small e this is approximately the difference in true anomaly), the central angle between spacecraft vector and the vector pointing towards $\Delta m$ from the Earth's center. Also given

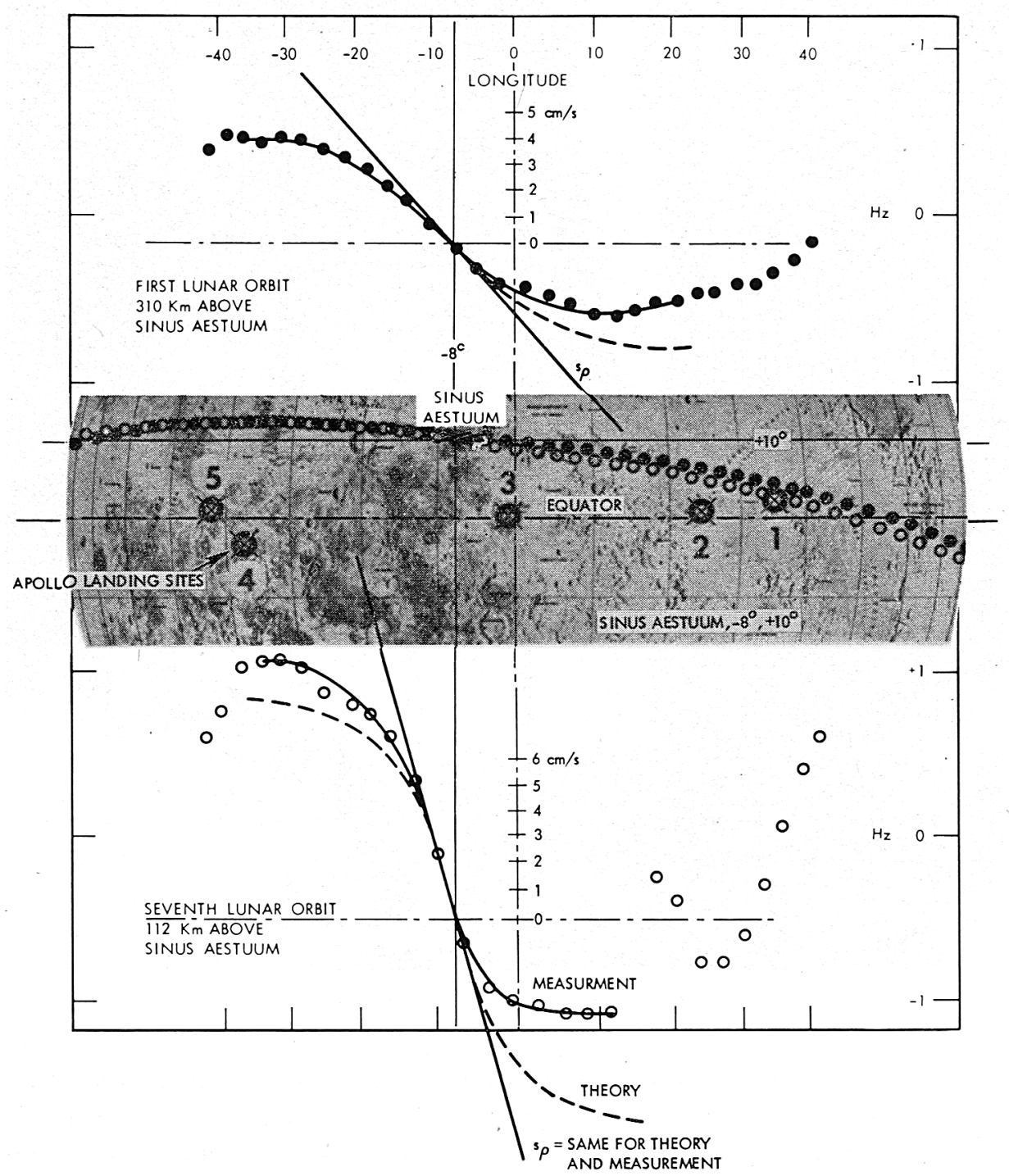

Fig. 7. Velocity variations $\Delta V_{\varrho}$ as a function of $\theta-\mathrm{a}$ comparison using Apollo 8 flight data (from von Bun, 1969). 


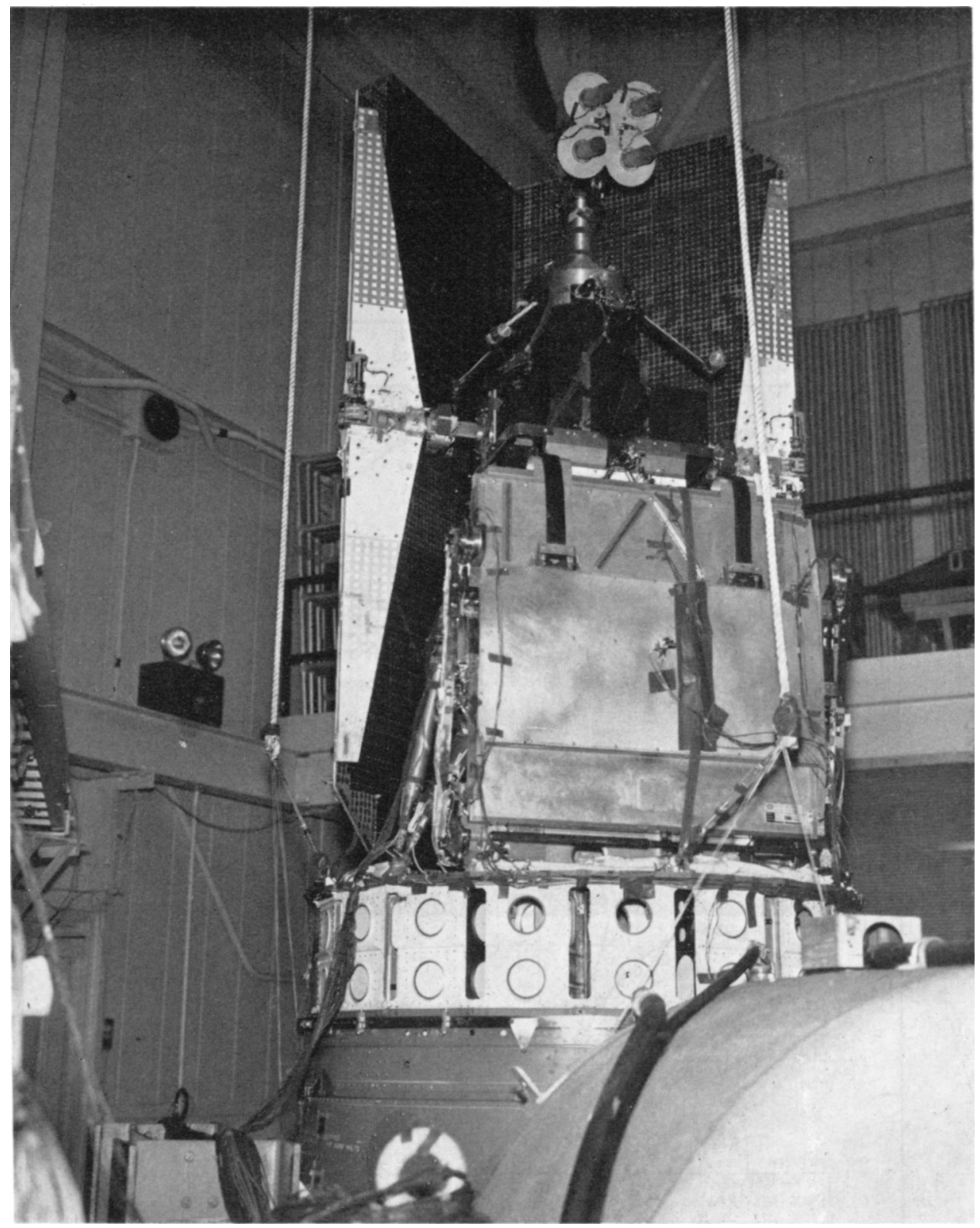

Fig. 8.

is the slope $s_{\theta}$ for $\Delta v_{\theta}$ at $\Delta \theta=0$, which is zero at this point. Further, as shown in Figure 5 , the spacecraft velocity changes up to $0.2 \mathrm{~cm} / \mathrm{s}$ during $\sim 4^{\circ}(\sim 400 \mathrm{~km})$ of spacecraft motion. Such a change should be measureable assuming the range rate error design goal of $0.03 \mathrm{~cm} / \mathrm{s}$ can be met for the system.

From Figure 6 it can be seen that the radial velocity change is almost equivalent 
to the same change in the range rate when the spacecraft and the anomaly are 'under' the synchronous spacecraft. Otherwise a trigonametric function is to be introduced as a multiplier. Using the Geopause (Siry, 1971) concept will just do this. Even with the NIMBUS spacecraft which is in a rather high orbit of, say, 800 to $1000 \mathrm{~km}$, as has been mentioned, one should be able for the first time to 'see' an Earth gravity anomaly (as on the Moon) such as exists for instance in the New Guinea area in the South Pacific. As an example, Equations (3) and (4) have been applied to the Apollo lunar case (Murphy and Siry, 1970). As can be seen from Figure 7, the radial velocity fits quite well and the slope fits extremely well.

This situation obviously improves when the near Earth spacecraft orbit height is decreased as shown in Figure 7 depicting the radial velocity slope $s_{Q}$ in $\mathrm{cm} \mathrm{s}^{-1} \mathrm{deg}^{-1}$.

If we assume it possible to orbit a spacecraft, equipped with a satellite-to-satellite

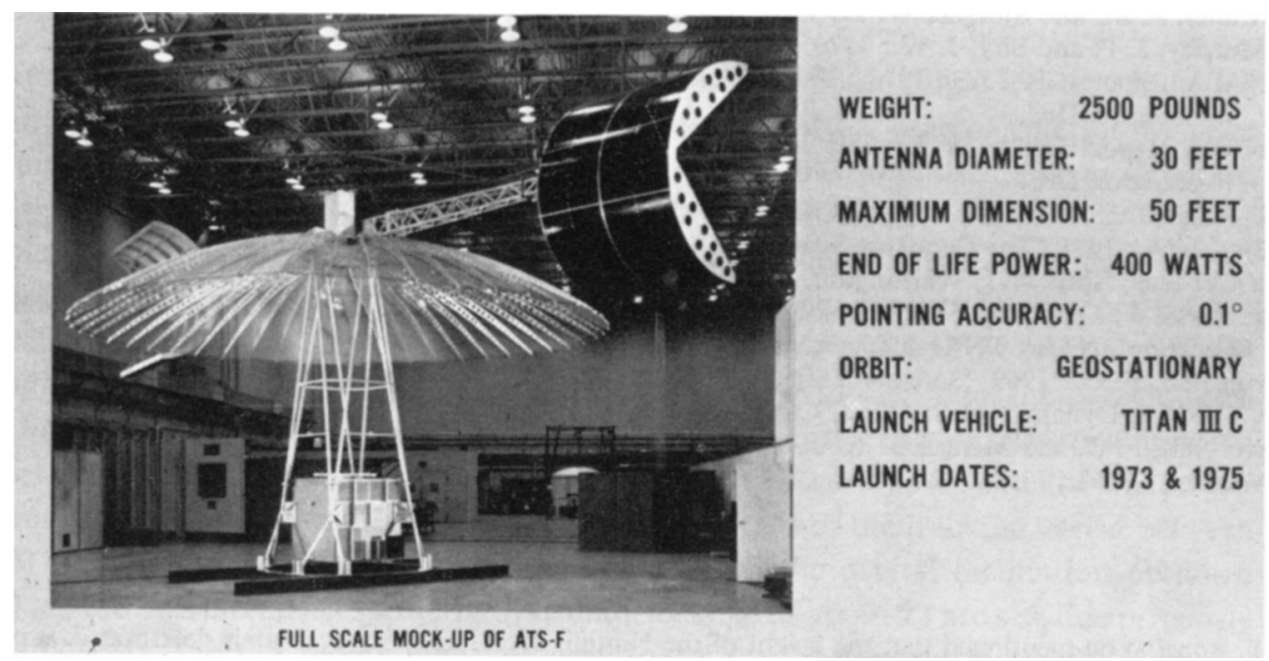

Fig. 9. ATS-F and G characteristics. Full scale mock-up of ATS-F.

tracking system at an orbital height of, say, $300 \mathrm{~km}$ and increase the system's range rate sensitivity from 0.03 to $0.01 \mathrm{~cm} / \mathrm{s}$ then we could increase the anomaly detection sensitivity by a factor of approximately 15 . Or in other words, gravity anomalies of 13 mgals may be globally detectable over short distances of, say, 200 to $400 \mathrm{~km}$. Further improvements can be accomplished by an even greater increase in sensitivity of the range rate system to say $0.001 \mathrm{~cm} / \mathrm{s}$ (over a $10 \mathrm{~s}$ smoothing time interval to quote a number). This would result in a global survey to approximately $1.3 \mathrm{mgals}$.

The value of $\delta \dot{r}=10^{-3} \mathrm{~cm} / \mathrm{s}$ quoted is not an impossibility. As shown in Murphy and Siry (1970):

$$
\stackrel{\delta \dot{r}}{\dot{r}}={ }_{\gamma}^{\delta \gamma}=\frac{1}{8} \times 10^{-8} \doteq 10^{-9}
$$

for a spacecraft speed of $\sim 8 \mathrm{~km} / \mathrm{s}$ has been obtained. A frequency measurement of $1 p$ 
in $10^{9}$ is feasible assuming a stable and low phase noise system and together with an integration time of say $10 \mathrm{~s}$ (Winkler, 1959).

Figures 8 and 9 show photographs of the NIMBUS-E and ATS satellites.

Note the special antenna of NIMBUS-E which will be used together with the $10 \mathrm{~m}$ ATS antenna for the experiment.

\section{References}

GSFC: 1969, Phase A Study, Final Report, 'GSFC Mark 1 - Tracking and Data-Relay Satellite (TDRS) Systems Concept', Goddard Space Flight Center.

Marsh, J. G.: 1971, 'A Unified Set of Tracking Station Coordinates from Geodetic Satellite Results', GSFC Report X-553-70-479, July 3, 1971.

Martin, C. F.: 1969, 'Accuracy of Satellite Orbits Obtainable by Synchronous Satellite Tracking', Dynamics of Satellite, COSPAR, Prague, 1969, p. 120.

Muller, P. M. and Sjorgen, W. L.: 1968, Science 161, 680.

Murphy, J. P. and Siry, J. W.: 1970, Planetary Space Sci. 18, 1137.

NASA Report CR-1579: 1970, 'The Terrestrial Environment: Solid Earth and Ocean Physics', Washington D.C.

NASA Report: 1971, 'A Possible Earth and Ocean Dynamics Satellite Applications Program', Washington D.C.

Parasnis, D. S.: 1961, Principles of Applied Geophysics, Methuen and Co., London.

Siry, J. W.: 1971, 'The Geopause Spacecraft Systems Concept', Proc. AGU, Symposium on Satellite Geodesy, April 1971, Washington, D.C.

von Bun, F. O.: 1968, 'Space Trajectories and Errors in Time, Frequency and Tracking Station Location', NASA TN D-4507, Washington; D.C., June 1968.

von Bun, F. O.: 1969, 'Satellite Trajectory Determination and Their Expected Errors', OGO IV, GEOS-I, Dynamics of Satellites, COSPAR, Prague, 1969, p. 89.

von Bun, F. O. and Mengel, J. T.: 1968, J. Spacecraft Rockets 5, 863.

Winkler, G. M.: 1959, J.R.E. 47.

\section{DISCUSSION}

Y. Kozai: You mentioned that the height of the Nimbus sarellite is very accurately determined. Is it the height above the surface?

$F$. $O$. von Bun: The height determined is not the absolute height, but its relative variation.

I. I. Mueller: Recent investigations at OSU by Dr Schwarz showed that if you can have $0.5 \mathrm{~mm} / \mathrm{s}$ satellite to satellite tracking and a $200 \mathrm{~km}$ satellite the maximum resolution obtainable is a $2^{\circ} \times 2^{\circ}$ mean anomaly at an accuracy similar to that obtainable from ground observations and/or predictions. 